\title{
EDITORIAL
}

\section{Why do we need yet another journal?}

\section{Enoka Corea and Nalika Gunawardena, Co-Editors}

The preceding decade has seen an exponential growth in the number of international and local journals publishing articles in relation to medicine. Notable features of this expansion have been an increase in the number of e-journals, local language journals and the mushrooming of publishing houses. So why add the Journal of the PGIM to this list?

The PGIM brings together postgraduate trainers and trainees in every discipline of medicine. A requirement of almost every Board of Study is a research component. These research studies are a rich repository of information and knowledge relevant to the practice of medicine in the local context. Many of these studies lie unpublished in the PGIM archives. One of the main intentions of the Journal of the PGIM is to facilitate the dissemination of this research.

Along with an increase in genuine, academic journals there has emerged a disturbing phenomenon of spurious journals. This was revealed when Science conducted a 'sting', submitting a spoof article to 304 open-access journal ${ }^{1}$. More than half the journals accepted it for publication at a fee, in spite of it having no scientific merit whatsoever! No peer review was done in many of the journals and minimal peer review in others. This publicity given to this scam has put the validity and quality of the peer review process under the spotlight. In contrast, the JPGIM provides a transparent and comprehensive peer review process.

One reason for the emergence of journals preying on researchers in the developing world is the lack of suitable good quality local journals that are willing to publish research relevant mainly in the local context or comprisingearly or pilot studies. A lack of English language and writing skills may result in good science being badly written and rejected prior to peer review. The JPGIM, on the other hand, includes in its aims the dissemination of local and preliminary research findings and the editorial board is committed to assisting the young clinical scientist taking his or her first plunge into publication, by providing a supportive group of experts ready to assist the first time author to craft a paper fit for dissemination among their peers.

Many young authors cannot afford the high author publication fees charged by online journals. At the JGPIM however, there is no charge for administration or review. The cost of administration is covered by the PGIM and editing and peer review are contributed by PGIM trainers on an honorary basis.

Although there are many medical journals listed on the website Sri Lanka Journals Online (http://www.sljol.info/), publicationis often delayed until a minimum number of articles are ready for publication. At the JPGIM, however, articles are published online as soon as the editing process is completed. This format, followed by many prestigious online journal such as PLOS ONE, ensures thatauthors do not have to face long delays before publicationand that current research is available promptly to readers.

We encourage the trainers and trainees of the various Boards of Study to take advantage of this opportunity to publish their research in the JPGIM.

\section{References}

1. Bohannon J. Who's afraid of peer review?Science 2013(6154);342: 60-5 